\title{
Crystal and Molecular Structure Analysis in Knoevenagel Condensation Product of Substituted Napthofuran-2-Carbaldehydes
}

\author{
Avantika Hasija1, V. Prakash², M. Shet Prakash ${ }^{3}$, Vasu', G. Krishnasamy5, Deepak Chopra1 ${ }^{*}$ \\ ${ }^{1}$ Crystallography and Crystal Chemistry Laboratory, Department of Chemistry, Indian Institute of Science Education and \\ Research Bhopal, Bhopal, Madhya Pradesh, India \\ ${ }^{2}$ Sri Sairam College of Engineering, Karnataka, India \\ ${ }^{3}$ Department of Studies and Research in Chemistry, University College of Science, Tumkur University, Tumakuru, Karnataka, \\ India \\ ${ }^{4}$ Vivekananda Degree College, Malleshwaram, Karnataka, India \\ ${ }^{5}$ Department of Studies and Research in Organic Chemistry, Tumkur University, Tumakuru, Karnataka, India \\ Email: ^dchopra@iiserb.ac.in
}

How to cite this paper: Hasija, A., Prakash, V., Prakash, M.S., Vasu, Krishnasamy, G. and Chopra, D. (2020) Crystal and Molecular Structure Analysis in Knoevenagel Condensation Product of Substituted Napthofuran-2-Carbaldehydes. Crystal Structure Theory and Applications, 9, 49-62. https://doi.org/10.4236/csta.2020.93005

Received: January 3, 2020

Accepted: August 1, 2020

Published: August 4, 2020

Copyright $\odot 2020$ by author(s) and Scientific Research Publishing Inc. This work is licensed under the Creative Commons Attribution International License (CC BY 4.0).

http://creativecommons.org/licenses/by/4.0/

\begin{abstract}
In the current study, two novel Knoevenagel condensation products of substituted napthofuran-2-carbaldehydes were designed, synthesized and characterized. In order to study the intermolecular interactions of title compounds, single crystals were grown by slow evaporation solution growth technique at room temperature and crystal structure has been determined by single crystal $\mathrm{X}$-ray diffraction technique. Both the molecules crystallize in the monoclinic centrosymmetric space group $P 2_{1} / c$ with one molecule in the asymmetric unit. In compound [4] the molecules are connected via bifurcated $\mathrm{C}-\mathrm{H} \cdots \mathrm{O}=\mathrm{C}$ and $\mathrm{C}-\mathrm{H} \cdots \mathrm{N}=\mathrm{C} \mathrm{H}$-bonds and van der Waals interactions forming a layered structure, whereas in compound [5a] the molecular conformation is stabilized via intramolecular $\mathrm{C}-\mathrm{H}$... $\mathrm{O} \mathrm{H}$-bond and molecule interacts with other molecule generated via $2{ }_{1}$-screw via bifurcated $\mathrm{C}-\mathrm{H} \cdots \mathrm{O}=\mathrm{C}$ along with $\mathrm{C}-\mathrm{H} \cdots \mathrm{N}=\mathrm{C}$ H-bonds, which are interacting with nitro- of other molecule generated via same symmetry operation, forming bifurcated $\mathrm{C}-\mathrm{H} \cdots \mathrm{O}-\mathrm{N}$ H-bonds, which helps in formation of molecular sheet-like structure. Further, in order to understand the various types and nature of intermolecular interactions in the supramolecular structure Hirshfeld surface analysis and fingerprint plot analysis was carried out.
\end{abstract}

\section{Keywords}

Napthofuran-2-Carbaldehyde, 8-Nitro Napthafura-2-Carbaldehyde, Knoevenagel Condensation, Single Crystal and Hirshfeld Surface 
Analysis

\section{Introduction}

Furan motif posses various pharmacological and biological activities such as antituberculosis [1], anti-inflammatory [2] and antibacterial [3] activities have attracted the attention of synthetic chemists. Also substituted benzofurans and naptho-furans find their applications in different fields such as fluorescent sensors [4], antioxidants [5], brightening agents, and a variety of drugs and agriculture [6]. Recently, Prashanth K. et al., reported the docking analysis of naphtho-furan and benzofuran derivatives and concluded that in most of the interactions involving the nitro group formed hydrogen bond with Asp16 of NarL protein and might act as a potential antitubercular lead molecule [7]. In addition to above, the crystallization phenomenon is very important in the pharmaceutical industry because it directly affects the bioavailability of drugs [8]. Furan-containing polycyclic aromatics are expected to provide relatively high HOMO levels [9] and offer utility in electronic devices such as organic light-emitting diodes (OLEDs) [10] and organic field-effect transistors (OFETs) [11]. Recently, dinaphtho [2,1-b:1',2'-d]furan [12] and dinaphtho [1,2-b:2',1'-d]furan [13] systems were developed and used in single-crystal OFETs and p-type semiconductors respectively. Also, chemistry of multiple bonds plays an important role in the organic synthesis. The Knoevenagel condensation reaction is one of the most important reactions in which $\mathrm{C}=\mathrm{C}$ bond is formed via condensation reactions of active methylene group with aldehydes or ketones that do not contain $\alpha$-hydrogen [14].

Based on the above importance and application of naptho-furan derivatives this manuscript reports the synthesis and crystal structures of two novel Knoevenagel condensation products of substituted napthofuran-2-carbaldehydes along with Hirshfeld surfaces and fingerprint plot analysis which has not been reported previously.

\section{Experimental}

\section{General remarks:}

All the chemicals used were purchased from Merck, Sigma Aldrich, SD fine and used without further purification. IR spectra were recorded in $\mathrm{KBr}$ pellets on a Perkin-Elmer Spectrometer. 1H NMR $(400 \mathrm{MHz})$ were run on a Bruker Avance DPX-250, FT-NMR spectrometer in $\mathrm{CDCl}_{3} / \mathrm{DMSO}^{-} \mathrm{d}_{6}$ as solvent and TMS as an internal standard. Melting points were recorded on a Stuart Scientific Apparatus SMP3 (UK) in open capillary tubes. The purity of the compounds was checked by TLC.

Preparation of Ethyl naphthofuran-2-carboxylate [1]

To a solution of 2-hydroxy-1-naphthaldehyde $(0.03 \mathrm{~mol})$ in dry $\mathrm{N}, \mathrm{N}$ dime- 
thylformamide $(25 \mathrm{ml})$, ethyl chloroacetate $(0.03 \mathrm{~mol})$ and anhydrous potassium carbonate $(0.9 \mathrm{~mol})$ were added and the reaction mixture was refluxed on water bath for $24 \mathrm{hrs}$. The reaction was monitored by TLC. After completion of reaction, the reaction mixture was then poured into ice cold water, to obtain the product ethyl naphthofuran-2-carboxylate as solid, which was collected by filtration, dried and recrystallized from ethanol [14].

Preparation of Naphthofuran-2-ylmethanol [2]

To a mixture of Lithium aluminum hydride $(0.04 \mathrm{~mol})$ in tetrahydrofuran $(5$ $\mathrm{mL})$, the solution of ethyl naphthofuran-2-carboxylate $(0.01 \mathrm{~mol})$ in THF $(5 \mathrm{~mL})$ was added slowly with continuous stirring at $0^{\circ} \mathrm{C}$. Stirring was continued for $2 \mathrm{~h}$ at room temperature. The completion of reaction was monitored by TLC. After completion of reaction, the reaction mixture was quenched in ammonium chloride solution. The product was extracted in ethyl acetate and purified through silica gel column chromatography [14].

Preparation of Naphthofuran-2-carbaldehyde [3]

Naphthofuran-2ylmethanol $(0.01 \mathrm{~mol})$ was dissolved in ethyl acetate $(7 \mathrm{~mL})$ and IBX $(0.03 \mathrm{~mol})$ was added. The resulting suspension was immersed in an oil bath set to $80^{\circ} \mathrm{C}$ and stirred vigorously with calcium chloride guard tube. After $3.5 \mathrm{~h}$ (TLC monitoring), the reaction was cooled to room temperature and filtered through a celite bed. The filter bed was washed with $3-2 \mathrm{ml}$ of ethyl acetate $(25 \mathrm{~mL})$, and the combined filtrates were concentrated to obtain naphthofuran-2-carbaldehyde [14].

Preparation of Ethyl-2-cyano-3-(naphthafuran-2-yl)acrylate [4]

Naphthofuran-2-carbaldehyde $(0.01 \mathrm{~mol})$ and ethylcyanoacetate $(0.02 \mathrm{~mol})$ were dissolved in ethyl alcohol $(10 \mathrm{~mL})$ in a round-bottomed flask and the resulting mixture was refluxed at $70^{\circ} \mathrm{C}$ for $10 \mathrm{~h}$. The completion of reaction was as indicated by TLC as well as separation of solid from reaction mixture. The separated solid product was filtered, dried and recrystallized from ethanol to get pure compound [14].

\section{Preparation of 8-Nitronaphtho[2,1-b]furan-2-carbaldehyde [4a]}

To a solution of Naphthofuran-2-carbaldehyde $(0.1 \mathrm{~mol})$ in glacial acetic acid $(20 \mathrm{ml})$, conc. $\mathrm{H}_{2} \mathrm{SO}_{4}(2 \mathrm{ml})$ was added followed by the addition of potassium nitrate $(2 \mathrm{~g})$ with stirring for $1 \mathrm{~h}$ at same temperature and the stirring was continued for $2 \mathrm{~h}$. The reaction mixture was poured into ice-cold water and the solid obtained was filtered out. It was washed with water, dried and the product was extracted in ethyl acetate and purified through silica gel column chromatography (EtOAc:n-Hexane-9:1).

Preparation of Ethyl-2-cyano-3-(5-nitronaphtho[2,1-b]furan-2-yl)acrylate [5a]

8-Nitro naphthofuran-2-carbaldehyde $(0.01 \mathrm{~mol})$ and ethylcyanoacetate $(0.02$ mol) were dissolved in ethyl alcohol $(10 \mathrm{~mL})$ in a round-bottomed flask and the resulting mixture was refluxed at $70^{\circ} \mathrm{C}$ for $10 \mathrm{hrs}$. The completion of reaction was as indicated by TLC as well as separation of solid from reaction mixture. 


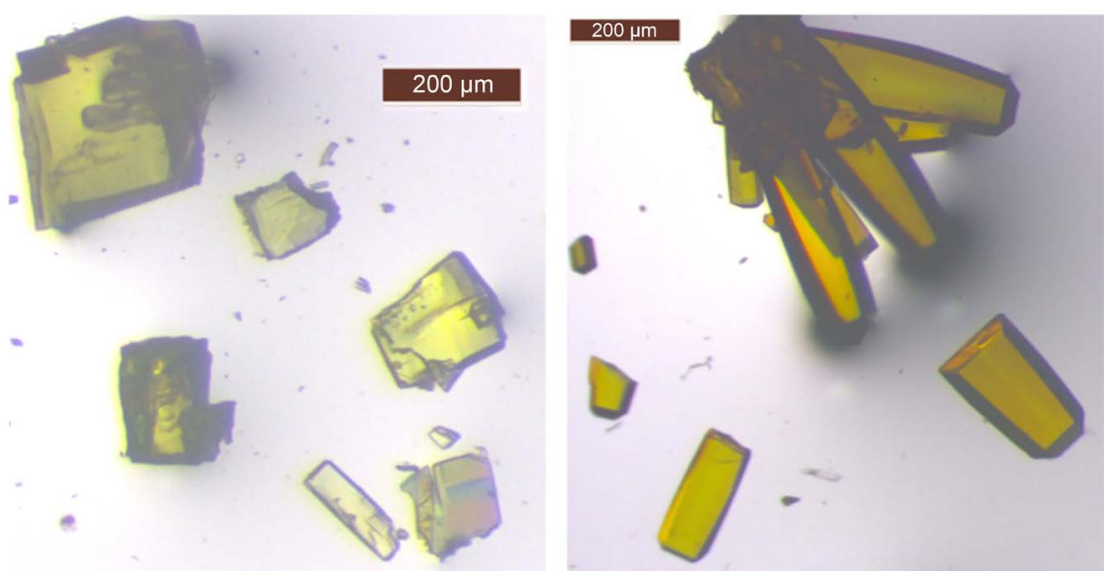

Figure 1. Morphology of single crystals of [4] (left) and [5a]. (Right) after crystallization in solvents $\alpha, \alpha, \alpha$-Trifluoro toluene and toluene respectively.

The separated solid product was filtered, dried and recrystallized from ethanol to get pure compound [5a].

Reagents and conditions: i) $\mathrm{ClCH}_{2} \mathrm{COOEt}, \mathrm{K}_{2} \mathrm{CO}_{3}, \mathrm{DMF}$, reflux; ii) $\mathrm{LiAlH}_{4}$, THF, $0^{\circ} \mathrm{C}$; iii) IBX, EtOAc, reflux; iv) $\mathrm{KNO}_{3}, \mathrm{H}_{2} \mathrm{SO}_{4} / \mathrm{AcOH}$, rt; v) Ethylcyanoacetate, $\mathrm{EtOH}, 70^{\circ} \mathrm{C}$.

\section{Method of crystallization}

$100 \mathrm{mg}$ of compound [4] and compound [5a] were dissolved in $15 \mathrm{~mL}$ of ethanol separately and warmed for $5 \mathrm{~min}$. The solution was filtered through Whatman filter paper and resulting solution was kept at room temperature $\left(22^{\circ} \mathrm{C}-23^{\circ} \mathrm{C}\right)$ in conical flask with stopper slightly open. The crystalline phase obtained after evaporation was again recrystallized via slow evaporation method with $\alpha, \alpha, \alpha$-trifluoro toluene for [4] and toluene for [5a]. After few days, the crystals of compound [4] and compound [5a] were developed; filtered and suitable crystals for single crystal analysis were selected. The morphology of the single crystals obtained for [4], [5a] are shown in Figure 1.

\section{Results and Discussion}

Synthesis of novel Knoevenagel condensation product of naphthofuran-2 carbaldehyde and 8-nitro napthafura-2-carbaldehyde with ethylcyanoacetate is depicted in Scheme 1. Spectroscopic characterization such as FTIR, ${ }^{1} \mathrm{HNMR}$ and mass spectral analysis confirms the assigned structures of the compound [14].

\section{Refinement:}

Single-crystal X-ray diffraction data were collected on a Bruker KAPPA APEX II DUO diffractometer using graphite-monochromated Mo- $\mathrm{K}_{\alpha}$ radiation $(\lambda=$ $0.71073 \AA$ A). Data collection was carried out at $100 \mathrm{~K}$ by an Oxford Cryostream cooling system using the Bruker Apex II software [15]. Cell refinement and data reduction were performed using the program SAINT [16]. The absorption correction was carried out using the program SADABS [17]. The structure was solved by direct methods using SHELXS-97 and refined by full-matrix least-squares methods 
based on $\mathrm{F}^{2}$ using SHELXL-2014 [18] [19]. All non-hydrogen atoms were refined anisotropically. The hydrogen atoms were placed in idealized positions

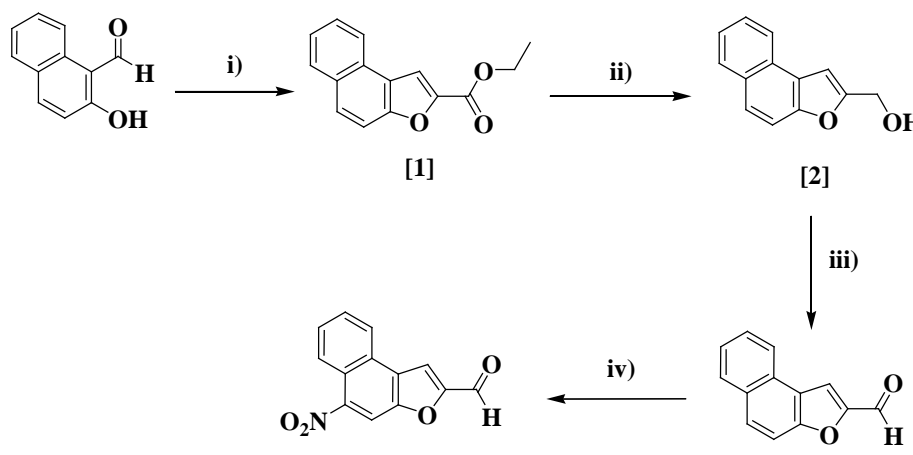

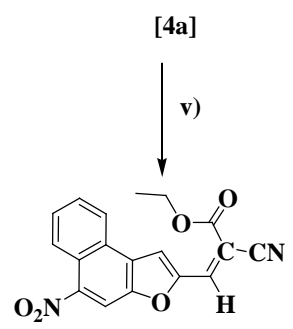

[5a]

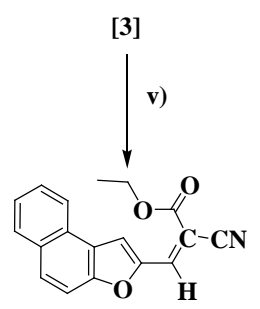

[4]

Scheme 1. Synthetic route for the Knoevenagel condensation product of napthofuran-2-carbaldehyde and 8-nitro napthafura-2-carbaldehyde.

Table 1. Crystallographic data and refinement parameters for [4] and [5a].

\begin{tabular}{|c|c|c|}
\hline & 4 & $5 a$ \\
\hline CCDC Number & 1868000 & 1868001 \\
\hline Molecular Formula & $\mathrm{C} 18 \mathrm{H} 13 \mathrm{~N} \mathrm{O} 3$ & $\mathrm{C} 18 \mathrm{H} 12 \mathrm{~N} 2 \mathrm{O} 5$ \\
\hline Molecular weight & 292.29 & 336.30 \\
\hline Temperature & 100 & 100 \\
\hline Crystal Size (mm) & $0.30,0.25,0.01$ & $0.45,0.30,0.2$ \\
\hline Absorption coefficient $\left(\mathrm{mm}^{-1}\right)$ & 0.094 & 0.108 \\
\hline $\mathrm{T}_{\min }, \mathrm{T}_{\max }$ & $0.972,0.999$ & $0.953,0.979$ \\
\hline Crystal system & Monoclinic & Monoclinic \\
\hline Lattice parameters: a $(\AA)$, b $(\AA)$, c $(\AA)$ & $\begin{array}{c}12.6075(10), 13.4863 \\
(11), 8.3764(7)\end{array}$ & $\begin{array}{c}13.9231(5), 13.4804(4) \\
8.5039(3)\end{array}$ \\
\hline$\alpha, \beta, \gamma\left(^{\circ}\right)$ & $90,97.358(6), 90$ & $90,104.793(2), 90$ \\
\hline Space Group, Density, Z, Z', F(000) & $P 2_{1} / \mathcal{C}, 1.370,4,1,608$ & $P 2_{1} / \mathcal{C}, 1.447,4,1,696$ \\
\hline $\mathrm{h}_{\min , \max } ; \mathrm{k}_{\min , \max } ; \mathrm{l}_{\min , \max }$ & $-17,17 ;-18,17 ;-11,11$ & $-16,16 ;-16,15 ;-10,10$ \\
\hline Number of total/unique/observed reflections & $21,374,4143,2684$ & $13,358,2704,2346$ \\
\hline No of parameters & 200 & 231 \\
\hline $\mathbf{R}_{\text {int }}$ & 0.0593 & 0.0321 \\
\hline $\mathbf{R}_{\text {all, }}, \mathbf{R}_{\text {obs }}$ & $0.0843,0.0500$ & $0.0536,0.0469$ \\
\hline$w R 2_{\text {all }}, w R 2_{\text {obs }}$ & $0.1447,0.1258$ & $0.1401,0.1346$ \\
\hline$\Delta \rho_{\max , \min }\left(e \AA^{-3}\right)$ & $0.359,-0.246$ & $0.741,-0.341$ \\
\hline G.o.F & 1.015 & 1.063 \\
\hline
\end{tabular}


and refined using a riding model with $\mathrm{U}_{\text {iso }}(\mathrm{H})=1.2$ Ueq $\left[\mathrm{C}_{\text {aromatic }}\right]$ and $U_{\text {iso }}(\mathrm{H})=$ 1.5 Ueq (methyl groups). Geometrical calculations were done using the PLATON [20]. ORTEP and packing diagrams were generated using the Mercury3.5.1 (CCDC) program [21]. The crystallographic and refinement data is tabulated in Table 1 and the list of inter and intra-molecular interactions for [4] and [5a] are collectively tabulated in Table 2 .

\section{Crystal Structure Analysis:}

The compound [4] crystallizes in the monoclinic centrosymmetric space group $P 2_{1} / c$ with one molecule in the asymmetric unit. Figure 2 gives the ORTEP view of the molecule.

All the bond angles and bond lengths are in accordance with values reported in the literature. The molecules are connected via bifurcated $\mathrm{C} 5 / 11-\mathrm{H} 5 / 11 \cdots \mathrm{O} 2=$ $\mathrm{C} 16$ and $\mathrm{C} 13-\mathrm{H} 13 \cdots \mathrm{N} 1=\mathrm{C} 15 \mathrm{H}$-bonds and van der Waals interactions forming a layered structure propagating along the b-axis (Figure 3). Parallel sheets are connected via $\mathrm{C} 17 \mathrm{~B}-\mathrm{H} 17 \mathrm{~B} \cdots \mathrm{N} 1=\mathrm{C} 15 \mathrm{H}$-bonds via an inversion center. There also exists stacking interactions between the sheets which are held via purely van der Waals interactions (Figure 4).

Table 2. List of intra and intermolecular contacts in compounds [4] and [5a].

\begin{tabular}{|c|c|c|c|c|c|}
\hline 4 & D-H $(\AA)$ & D-A $(\AA)$ & $\mathrm{H} \cdots \mathrm{A}(\AA)$ & $\mathrm{D}-\mathrm{H} \cdots \mathrm{A}\left({ }^{\circ}\right)$ & Symmetry \\
\hline $\mathrm{C} 5-\mathrm{H} 5 \cdots \mathrm{O} 2$ & 0.95 & 3.370 & 2.43 & 172 & $-x+1,+y-1 / 2,-z+1 / 2+1$ \\
\hline $\mathrm{C} 13-\mathrm{H} 13 \cdots \mathrm{N} 1$ & 0.95 & 3.408 & 2.49 & 164 & $-\mathrm{x}+1,+\mathrm{y}-1 / 2,-\mathrm{z}+1 / 2+1$ \\
\hline $\mathrm{C} 11-\mathrm{H} 11 \cdots \mathrm{O} 2$ & 0.95 & 3.311 & 2.42 & 157 & $-\mathrm{x}+1,+\mathrm{y}-1 / 2,-\mathrm{z}+1 / 2+1$ \\
\hline $\mathrm{C} 17-\mathrm{H} 17 \mathrm{~B} \cdots \mathrm{N} 1$ & 0.99 & 3.500 & 2.64 & 145 & $-x+1,-y+1,-z+2$ \\
\hline $5 a$ & D-H $(\AA)$ & D-A $(\AA)$ & $\mathrm{H} \cdots \mathrm{A}(\AA)$ & $\mathrm{D}-\mathrm{H} \cdots \mathrm{A}\left({ }^{\circ}\right)$ & Symmetry \\
\hline $\mathrm{C} 3-\mathrm{H} 3 \cdots \mathrm{O} 5$ & 0.95 & 3.391 & 2.45 & 173 & $-x+1,+y+1 / 2,-z+1 / 2+2$ \\
\hline $\mathrm{C} 5-\mathrm{H} 5 \cdots \mathrm{O} 2$ & 0.95 & 3.335 & 2.39 & 175 & $-x+2,+y+1 / 2,-z+1 / 2+1$ \\
\hline $\mathrm{C} 13-\mathrm{H} 13 \cdots \mathrm{N} 1$ & 0.93 & 3.374 & 2.48 & 161 & $-x+2,+y+1 / 2,-z+1 / 2+1$ \\
\hline $\mathrm{C} 11-\mathrm{H} 11 \cdots \mathrm{O} 2$ & 0.95 & 3.320 & 2.43 & 157 & $-x+2,+y+1 / 2,-z+1 / 2+1$ \\
\hline $\mathrm{C} 17-\mathrm{H} 17 \mathrm{~A} \cdots \mathrm{N} 1$ & 0.99 & 3.515 & 2.65 & 146 & $-x+2,-y,-z+1$ \\
\hline 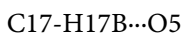 & 0.99 & 3.363 & 2.44 & 155 & $-x+2,-y,-z+2$ \\
\hline $\mathrm{C} 2-\mathrm{H} 2 \cdots \mathrm{O} 4$ & 0.95 & 2.794 & 2.18 & 122 & $\mathrm{x}, \mathrm{y}, \mathrm{z}$ \\
\hline
\end{tabular}

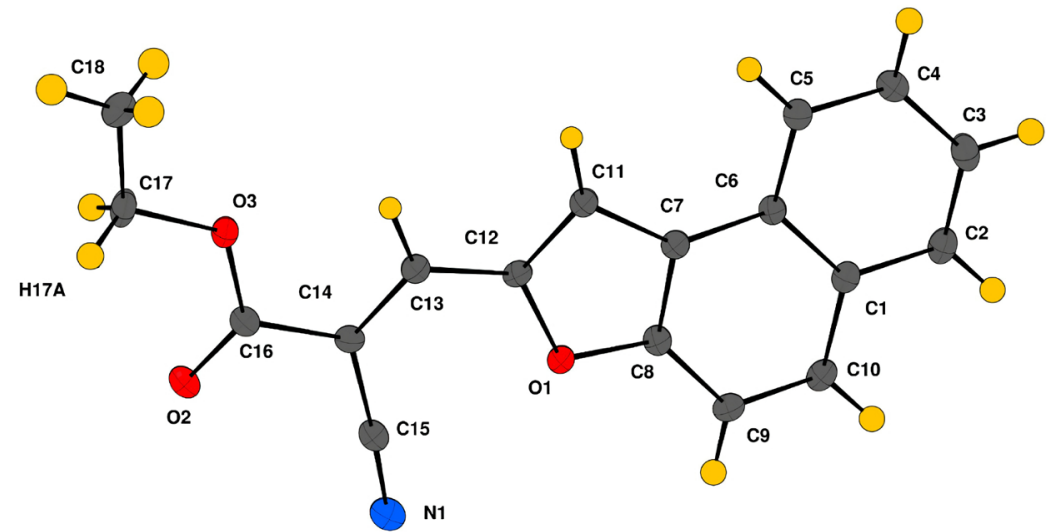

Figure 2. ORTEP representation (with 50\% displacement ellipsoids) of [4] showing the atom numbering scheme. 


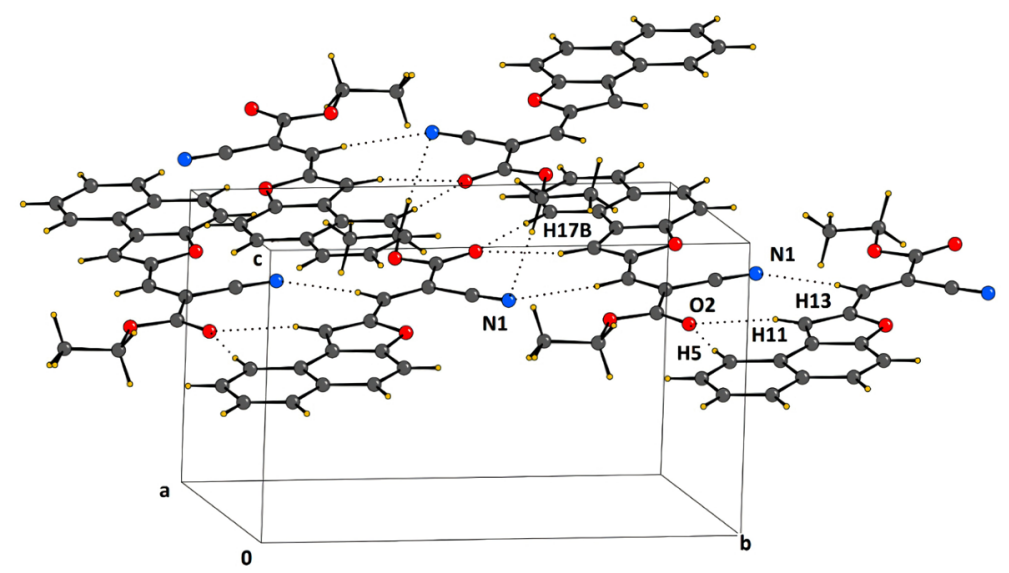

Figure 3. Packing arrangement of molecules in the crystal structure via $\mathrm{C}-\mathrm{H} \cdots \mathrm{O}$ and $\mathrm{C}-\mathrm{H} \cdots \mathrm{N}$ intermolecular interactions in [4].

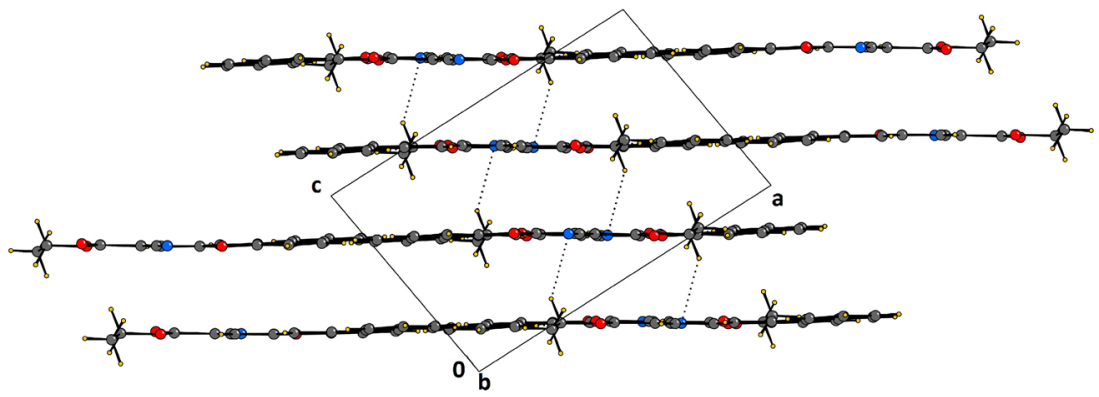

Figure 4. Layered packing arrangement of molecules in the crystal structure via $\mathrm{C}-\mathrm{H} \cdots \mathrm{N}$ intermolecular interactions in between the sheets in [4].

The molecule [5a] crystallizes in the centrosymmetric space group $P 2_{1} / c$ with one molecule in the asymmetric unit. Figure 5 gives the ORTEP view of the molecule. The molecular conformation is stabilized via intramolecular $\mathrm{C} 2-\mathrm{H} 2 \ldots \mathrm{O} 4$ $\mathrm{H}$-bond. The molecule interacts with other molecule generated via $2_{1}$-screw bifurcated $\mathrm{C} 5 / 11-\mathrm{H} 5 / 11 \cdots \mathrm{O} 2=\mathrm{C} 16$ along with $\mathrm{C} 13-\mathrm{H} 13 \cdots \mathrm{N} 1=\mathrm{C} 15 \mathrm{H}$-bonds, which are interacting with nitro- of other molecule generated via same symmetry operation, forming bifurcated $\mathrm{C} 3-\mathrm{H} 3 \cdots \mathrm{O} 4 / \mathrm{O} 5-\mathrm{N} 2 \mathrm{H}$-bonds, which helps in formation of molecular sheet-like structure (Figure 6). The parallel sheets related via an inversion center are held via additional C17A-H17A...N1, C17B-H17B-..O5 $\mathrm{H}$-bonds. The parallel sheets are molecular stacked, stabilizing the overall packing (Figure 7).

The overall conformation of [4] and [5a] are nearly similar, with slight distortion in C18 methyl group in [5a]. The molecule [5a] is nearly planar with the -nitro group slightly deviated from the mean plane of the molecule.

\section{Hirshfeld Surface analysis:}

Crystal of compound [4] is primarily assembled via bifurcated C5/11-H5/ $11 \cdots \mathrm{O} 2$ and $\mathrm{C} 13 \mathrm{H} 13 \cdots \mathrm{N} 1=\mathrm{C} 15$ related to the next molecule via inversion centre. These majorly competent interactions could also be visualised through the Hirshfeld Surface Analysis, a module of Crystal Explorer (Version 17.5.), which 


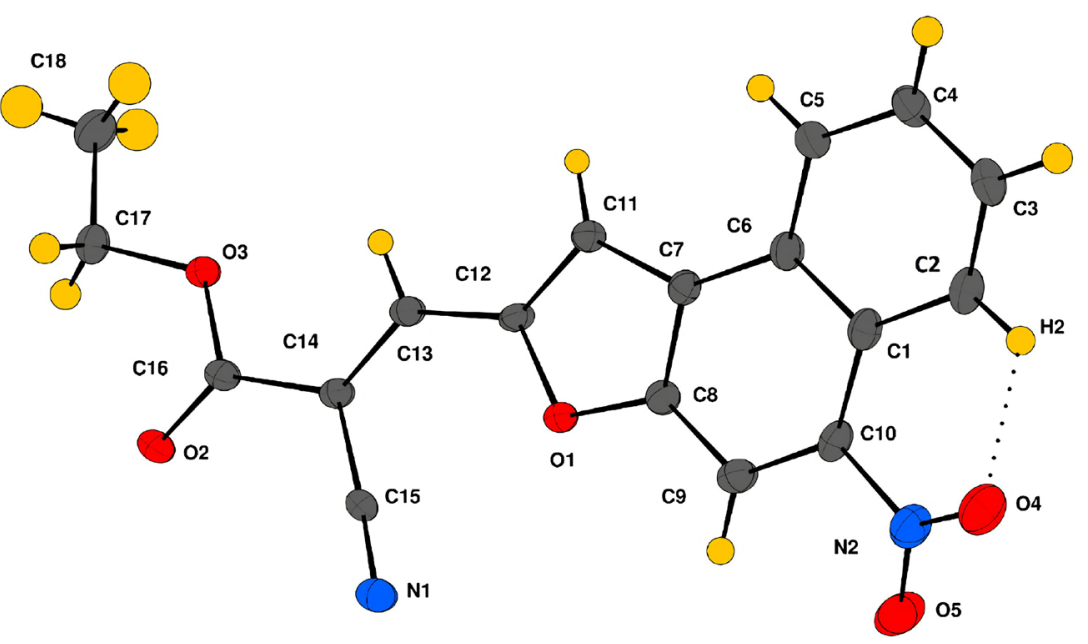

Figure 5. ORTEP representation (with 50\% displacement ellipsoids) of [5a] showing the atom numbering scheme. The dotted lines indicate intramolecular $\mathrm{C} 2-\mathrm{H} 2 \cdots \mathrm{O} 4-\mathrm{N} 2$ (nitro) H-bond.

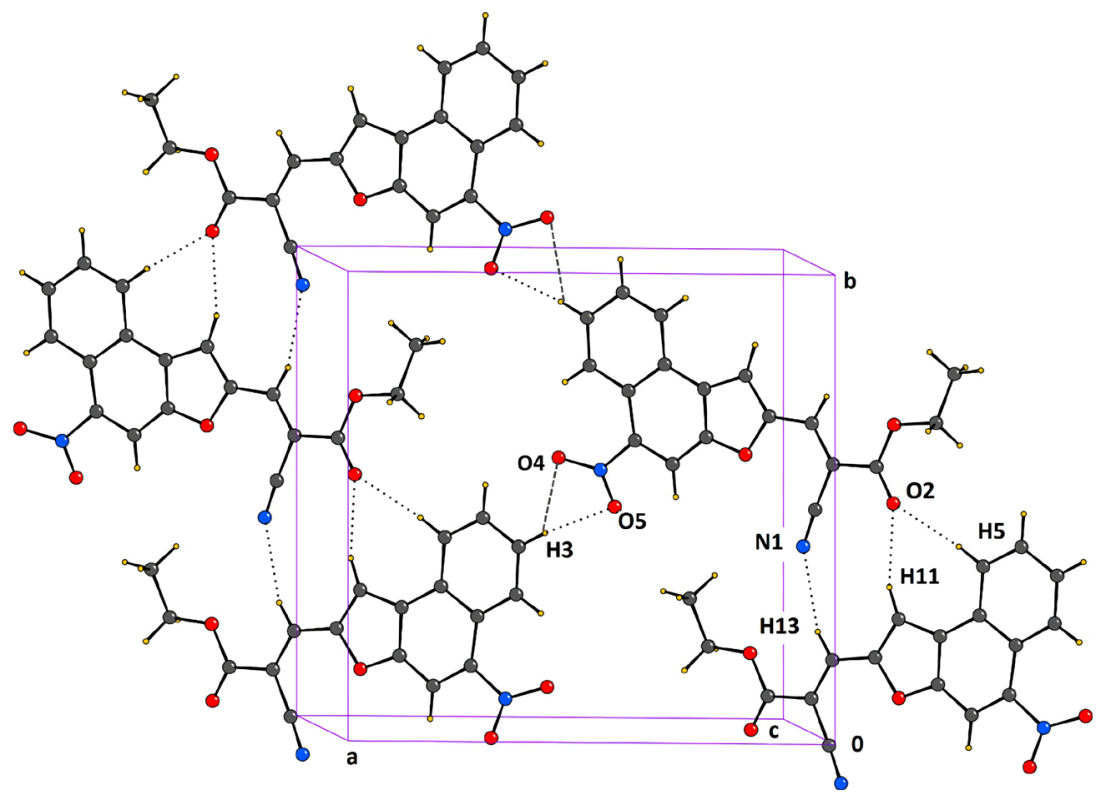

Figure 6. Crystal packing depicting sheet formation in molecule of [5a]. The dotted lines indicate $\mathrm{C}-\mathrm{H} \cdots \mathrm{O}$ and $\mathrm{C}-\mathrm{H} \cdots \mathrm{N}$ intermolecular interactions.

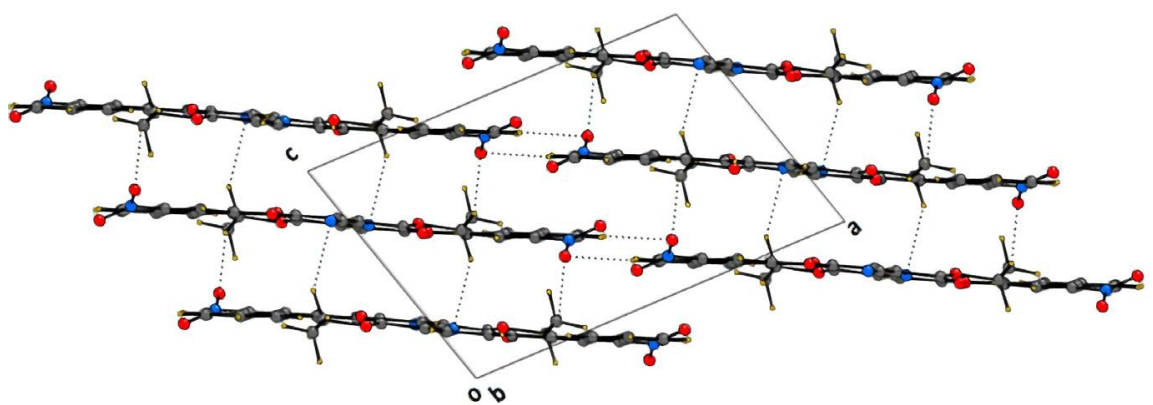

Figure 7. Layered packing arrangement in molecule of [5a]. The inter sheets are connected via $\mathrm{C}-\mathrm{H} \cdots \mathrm{O}$ and $\mathrm{C}-\mathrm{H} \cdots \mathrm{N}$ intermolecular interactions. 
shows the red region as a plausible region for interactions [22] [23]. Figure 8(a) shows the red region on the Hirshfeld surface of [4] forming bifurcated C-H...O and $\mathrm{C}-\mathrm{H} \cdots \mathrm{N}$ and thereby stabilizing the sheet, which is connected to other parallel sheets via molecular stacking and $\mathrm{C} 17-\mathrm{H} 17 \mathrm{~B} \cdots \mathrm{N} 1=\mathrm{C} 15$ (Figure 8(b)).
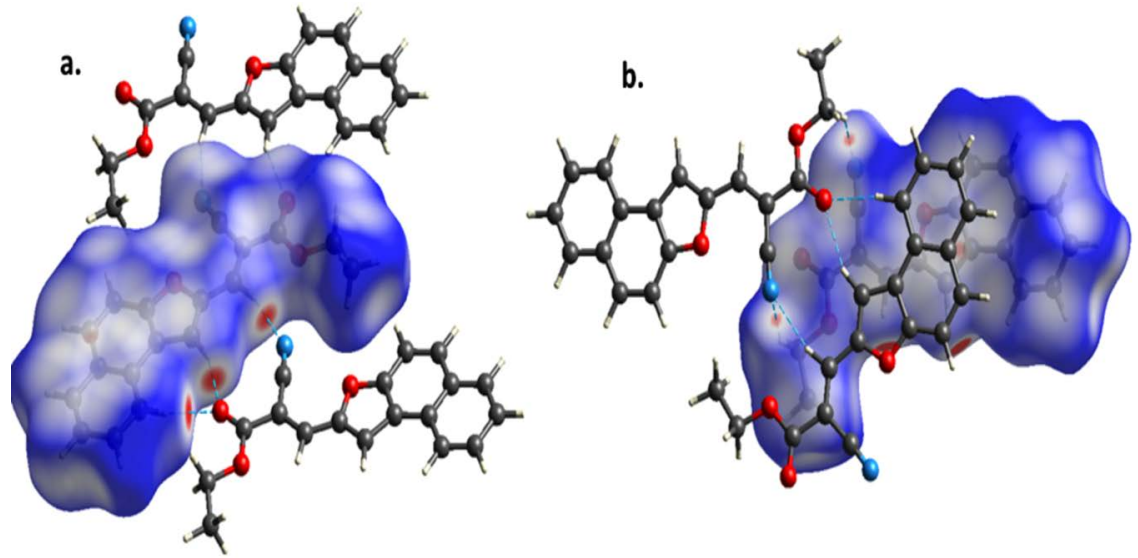

Figure 8. $\mathrm{d}_{\text {norm }}$ mapped on the Hirshfeld surface for visualising (a) $\mathrm{C}-\mathrm{H} \cdots \mathrm{O}$ and $\mathrm{C}-\mathrm{H} \cdots \mathrm{N}$ $\mathrm{H}$-bond; (b) C-H...N and molecular stacking; of [4]. The dotted line represents hydrogen bonds.

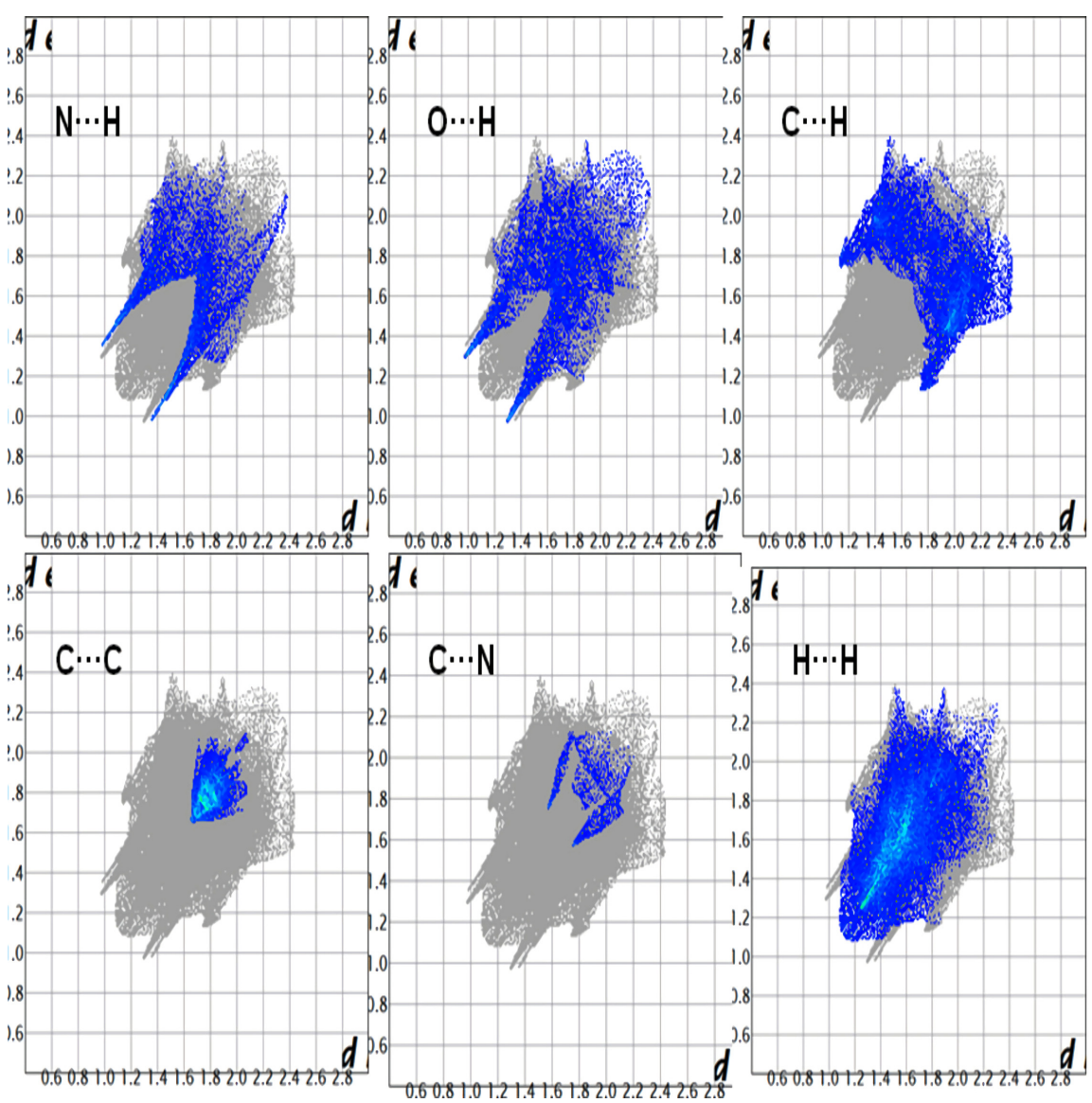

Figure 9. Fingerprint plot for compound [4] showing contribution of $\mathrm{N} \cdots \mathrm{H} / \mathrm{H} \cdots \mathrm{N}$, $\mathrm{O} \cdots \mathrm{H} / \mathrm{H} \cdots \mathrm{O}, \mathrm{C} \cdots \mathrm{H} / \mathrm{H} \cdots \mathrm{C}, \mathrm{C} \cdots \mathrm{C}, \mathrm{C} \cdots \mathrm{N} / \mathrm{N} \cdots \mathrm{C}, \mathrm{H} \cdots \mathrm{H}$ contacts. 
The individual contribution of different interactions is well elucidated via a module of Crystal Explorer named Fingerprint plot (Figure 9). The contribution of various contacts such as $\mathrm{N} \cdots \mathrm{H} / \mathrm{H} \cdots \mathrm{N}(10.4 \%), \mathrm{O} \cdots \mathrm{H} / \mathrm{H} \cdots \mathrm{O}(12.5 \%), \mathrm{C} \cdots \mathrm{H} / \mathrm{H} \cdots \mathrm{C}$

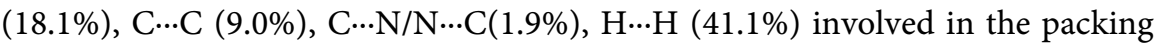
signifies the importance of individual contacts in the overall stabilization of the crystal lattice.

Compound [5a] is stabilized primarily via short $\mathrm{H}$-bonds involving $\mathrm{C}-\mathrm{H}$-..O and $\mathrm{C}-\mathrm{H} \cdots \mathrm{N}$ interactions which are well represented through the Hirshfeld surface analysis. The red region depicts the plausible interactions for the above-mentioned compound. Figure 10(a) clearly depicts that the major interactions responsible for stability of the compound are $\mathrm{C}-\mathrm{H} \cdots \mathrm{O}$ and $\mathrm{C}-\mathrm{H} \cdots \mathrm{N}$, which are also mentioned above in the packing analysis. The surface analysis also corroborates with the role of bifurcated $\mathrm{C}-\mathrm{H} \cdots \mathrm{O}$ and short $\mathrm{C}-\mathrm{H} \cdots \mathrm{N}=\mathrm{C}$ hydrogen bonds in the stabilization of this motif (Figure 10(b)).

The qualitative picture of contribution of contacts involved in the assembly of crystal lattice of compound [5a] is also given by Fingerprint Plot. The qualitative overview of interactions involved in crystal packing of compound [5a] is as follows $\mathrm{N} \cdots \mathrm{H} / \mathrm{H} \cdots \mathrm{N}(10.0 \%), \mathrm{O} \cdots \mathrm{H} / \mathrm{H} \cdots \mathrm{O}(25.5 \%), \mathrm{C} \cdots \mathrm{H} / \mathrm{H} \cdots \mathrm{C}(15.9 \%), \mathrm{C} \cdots \mathrm{C}(8.2 \%)$, $\mathrm{C} \cdots \mathrm{N} / \mathrm{N} \cdots \mathrm{C}(2.7 \%)$ and $\mathrm{H} \cdots \mathrm{H}(27.5 \%)$ (Figure 11$)$.

\section{Cambridge Structural Database study:}

A database search using Cambridge Structural Database [24] was carried out, to recognize the importance of structural study in molecules consisting of the "naptho-furan" skeleton. A total of 11 hits were found including only one structural report (LERXEN) with substitution of -Br [25] at C10 and a few structural reports (OCELIT, OCEHOV, TAGZUZ, IYUPID, IDUNIF, DAVQUO) involving molecules substituted at C12 comprising of the carbonyl group [26] [27] [28] [29]. LERXEN, having a-Br at $\mathrm{C} 10$, forms $\mathrm{C}-\mathrm{H} \cdots \mathrm{Br}$ and halogen contacts, instead of $\mathrm{C}-\mathrm{H}$... O as was observed in case of the -Nitro group in [5a]. Similarly, in case of DAVQUO, the C12 position is substituted with -COOEt which has higher propensity of forming $\mathrm{C}-\mathrm{H}$... O and van der Waals contacts than that observed in [4], which has a $-\mathrm{CH}_{2} \mathrm{C}(\mathrm{CN})(\mathrm{COOEt})$ group. The limited structural studies till

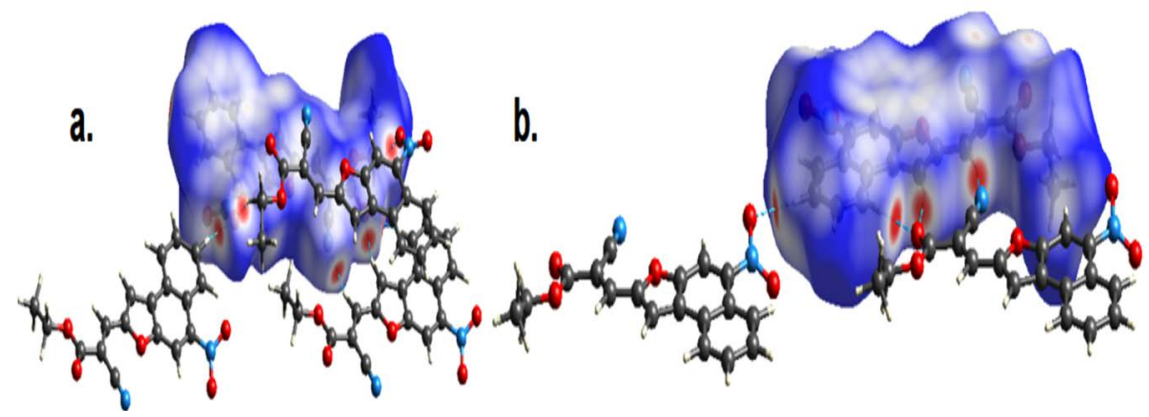

Figure 10. $d_{\text {norm }}$ mapped on the Hirshfeld surface for visualising (a) C-H...O and C-H...N $\mathrm{H}$-bond and molecular stacking; (b) $\mathrm{C}-\mathrm{H} \cdots \mathrm{N}$ and $\mathrm{C}-\mathrm{H} \cdots \mathrm{O}$ of compound [5a]. The dotted line represents hydrogen bonds. 

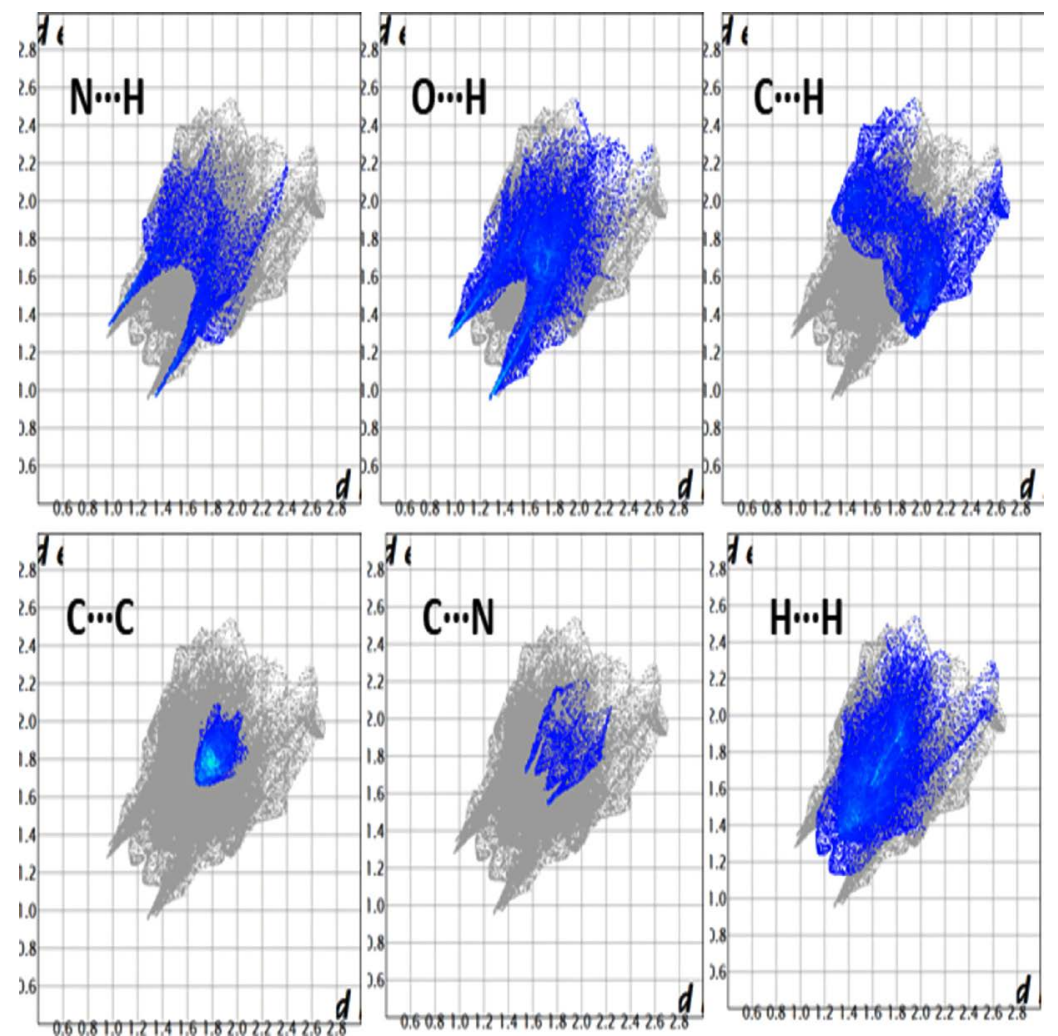

Figure 11. Fingerprint plot for compound [5a] showing contribution of $\mathrm{N} \cdots \mathrm{H} / \mathrm{H} \cdots \mathrm{N}$, $\mathrm{O} \cdots \mathrm{H} / \mathrm{H} \cdots \mathrm{O}, \mathrm{C} \cdots \mathrm{H} / \mathrm{H} \cdots \mathrm{C}, \mathrm{C} \cdots \mathrm{C}, \mathrm{C} \cdots \mathrm{N} / \mathrm{N} \cdots \mathrm{C}, \mathrm{H} \cdots \mathrm{H}$ contacts.

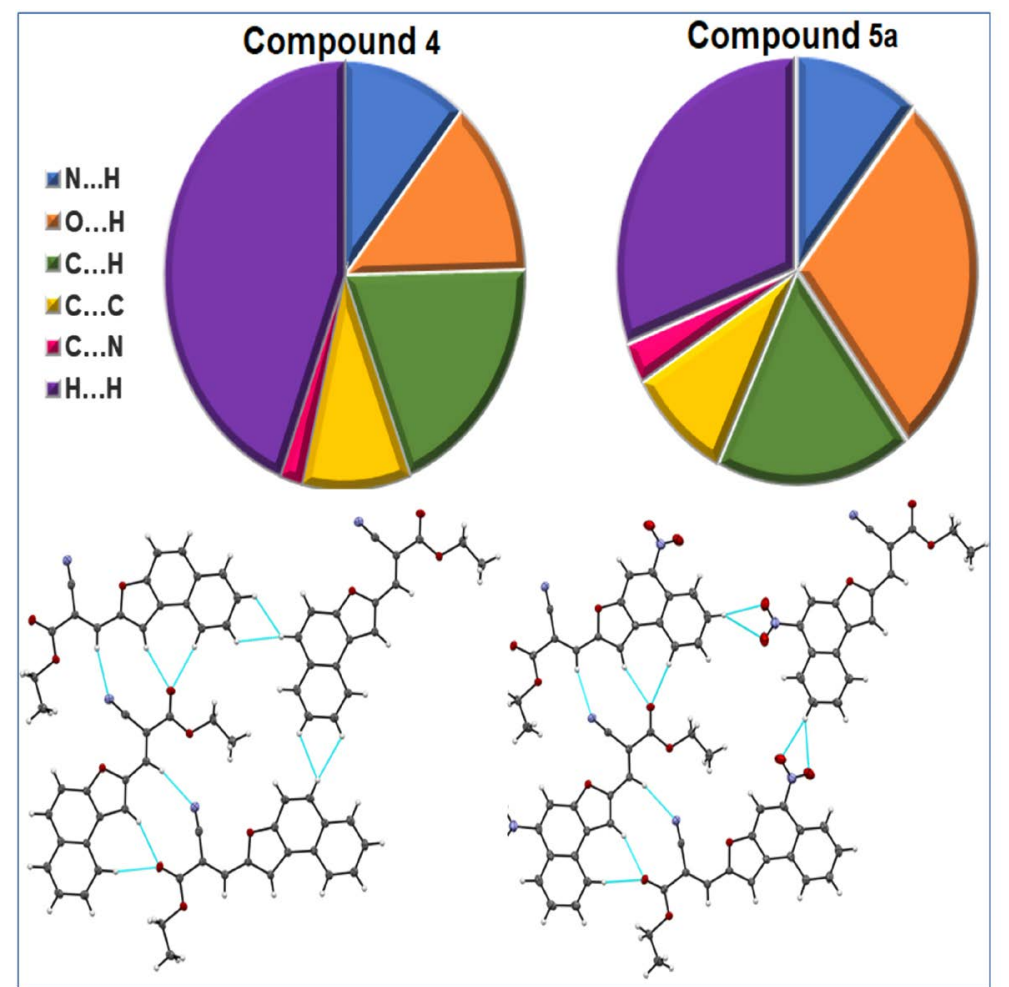

Figure 12. Comparison in contribution of varied interactions involved in stabilization of compound [4] and [5a]. 
date in "naptho-furan" containing scaffolds illustrates that these molecules are yet to be explored in terms of their structural and molecular diversity. This includes a systematic examination of the molecular conformation and the plethora of conventional and non-conventional non-covalent interactions which results in the formation of molecular crystals.

Comparison in packing of compound [4] and [5a]:

Compound [4] stabilized via $\mathrm{C}-\mathrm{H} \cdots \mathrm{O}$ and $\mathrm{C}-\mathrm{H} \cdots \mathrm{N}$, also shows relatively more contribution from $\mathrm{H} \cdots \mathrm{H}$ contacts (Figure 12) in comparison to compound [5a], due to the introduction of $-\mathrm{NO}_{2}$ group at $\mathrm{C} 10$. The nitro substitution in compound [5a] leads to more contribution from $\mathrm{O} \cdots \mathrm{H}$ interactions which can be visualised through Figure 12.

\section{Conclusion}

The wide scope of furan and naptho-furan consisting molecules in electronic devices, pharmacological and biological activities, has intrigued researchers to explore such systems further, in order to gain invaluable structural insights. The structural investigation gives us the platform for unraveling the role of various intermolecular interactions such as $\mathrm{C}-\mathrm{H} \cdots \mathrm{O}, \mathrm{C}-\mathrm{H} \cdots \mathrm{N}$, van der Waals contacts, etc. that are involved in the overall formation of the crystal. In summary we have synthesized two novel Knoevenagel condensation products of substituted napthofuran-2-carbaldehydes. Spectroscopic characterization such as FTIR, ${ }^{1} \mathrm{H}$ NMR and mass spectral analysis confirms the assigned structures of the compound. Single crystal X-ray diffraction analysis reveals that both the molecules crystallize in the monoclinic centrosymmetric space group $P 2_{1} / c$ with one molecule in the asymmetric unit. The crystal surface analysis carried out by Hirshfeld surface studies and fingerprint plot analysis, which facilitates in understanding the type and nature of intermolecular interactions and as well as packing in the solid-state.

\section{Acknowledgements}

The authors are thankful to Department of Studies and Research in Chemistry, UCS, Tumkur University, Tumakur and thankful to Tumkur University for providing the laboratory facilities. AH thanks IISER Bhopal for research fellowship. We are thankful to IISER Bhopal for research facilities and infrastructure.

\section{Conflicts of Interest}

The authors declare no conflicts of interest regarding the publication of this paper.

\section{References}

[1] Tawari, N.R., Bairwa, R., Ray, M.K., Rajan, M.G.R. and Degani, M.S. (2010) Design, Synthesis, and Biological Evaluation of 4-(5-nitrofuran-2-yl)prop-2-en-1-one Derivatives as Potent Antitubercular Agents. Bioorganic \& Medicinal Chemistry Letters, 20, 6175-6178. https://doi.org/10.1016/j.bmcl.2010.08.127 
[2] Shin, J.S., Park, S.J., Ryu, S., Kang, H.B., Kim, T.W., Choi, J.H., Lee, J.Y., Cho, Y.W. and Lee, K.T. (2011) Potent Anti-Inflammatory Effect of a Novel Furan-2,5-dione Derivative, BPD, Mediated by Dual Suppression of COX-2 Activity and LPS-Induced Inflammatory Gene Expression via NF- $\kappa$ B Inactivation. British Journal of Pharmacolo$g y$, 165, 1926-1940. https://doi.org/10.1111/j.1476-5381.2011.01670.x

[3] Kirilmis, C., Ahmedzade, M., Servi, S., Koca, M., Kizirgil, A. and Kazaz, C. (2008) Synthesis and Antimicrobial Activity of Some Novel Derivatives of Benzofuran: Part 2. The Synthesis and Antimicrobial Activity of Some Novel 1-(1-benzofuran-2-yl)-2-mesitylethanone Derivatives. European Journal of Medicinal Chemistry, 43, 300-308. https://doi.org/10.1016/j.ejmech.2007.03.023

[4] Oter, O., Ertekin, K., Kirilmis, C., Koca, M. and Ahmedzade, M. (2007) Characterization of a Newly Synthesized Fluorescent Benzofuran Derivative and Usage as a Selective Fiber Optic Sensor for Fe(III). Sensors and Actuators B, 122, 450-456. https://doi.org/10.1016/j.snb.2006.06.010

[5] Sindhe, M.A., Bodke, Y.D., Kenchappa, R., Telkar, S. and Chadrashekar, A. (2016) Synthesis of a Series of Novel 2,5-Disubstituted-1.3.4-oxadiazole Derivatives as Potential Antioxidant and Antibacterial Agents. Journal of Chemical Biology, 9, 79-90. https://doi.org/10.1007/s12154-016-0153-9

[6] Keay, B.A., Hopkins, J.M. and Dibble, P.W. (2008) Furans and Their Benzo Derivatives: Applications. In: Comprehensive Heterocyclic Chemistry II, Elsevier, Amsterdam, 571-624. https://doi.org/10.1016/B978-008044992-0.00308-4

[7] Prashantha, K., Girija, C.R., Krishnamurthy, V., Krishna, V. and Shivakumar, K.V. (2014) In Silico Antitubercular Activity Analysis of Benzofuran and Naphthofuran Derivatives. Tuberculosis Research and Treatment, 2014, Article ID: 697532. https://doi.org/10.1155/2014/697532

[8] Emami, S., Siahi-Shadbad, M., Adibkia, K. and Barzegar-Jalali M. (2018) Recent Advances in Improving Oral Drug Bioavailability by Cocrystals. BioImpacts, 8, 305-320. https://doi.org/10.15171/bi.2018.33

[9] Bunz, U.H.F. (2010) $\alpha$-Oligofurans: Molecules without a Twist. Angewandte Chemie International Edition, 49, 5037-5040. https://doi.org/10.1002/anie.201002458

[10] Tsuji, H., Mitsui, C., Ilies, L., Sato, Y. and Nakamura, E. (2007) Synthesis and Properties of 2,3,6,7-Tetraarylbenzo[1,2-b:4,5-b']difurans as Hole-Transporting Material. Journal of the American Chemical Society, 129, 11902-11903. https://doi.org/10.1021/ja074365w

[11] Mitsui, C., Soeda, J., Miwa, K., Tsuji, H., Takeya, J. and Nakamura, E. (2012) Naphtho[2,1-b:6,5-b']difuran: A Versatile Motif Available for Solution-Processed Single-Crystal Organic Field-Effect Transistors with High Hole Mobility. Journal of the American Chemical Society, 134, 5448-5451. https://doi.org/10.1021/ja2120635

[12] Nakahara, K., Mitsui, C., Okamoto, T., Yamagishi, M., Miwa, K., Sato, H., Yamano, A., Uemura, T. and Takeya, J. (2013) Single-Crystal Field-Effect Transistors with a Furan-Containing Organic Semiconductor Having a Twisted $\pi$-Electronic System. Chemistry Letters, 42, 654-656. https://doi.org/10.1246/cl.130133

[13] Mitsui, C., Okamoto, T., Matsui, H., Yamagishi, M., Matsushita, T., Soeda, J., Miwa, K., Sato, H., Yamano, A., Uemura, T. and Takeya, J. (2013) Dinaphtho[1,2-b:2',1'-d]chalcogenophenes: Comprehensive Investigation of the Effect of the Chalcogen Atoms in the Phenacene-Type $\pi$-Electronic Cores. Chemistry of Materials, 25, 3952-3956. https://doi.org/10.1021/cm303376g

[14] ShetPrakash, M., Krishnaswamy, G., Ravi, D., Lavanya, K.N. and Priyanka, M. (2018) Synthesis and Characterisation of Novel Knoevenagel Condensation Product 
of Naphthofuran-2-carbaldehyde with Barbituric Acid and Ethylcyanoacetate. Journal of Chemical and Pharmaceutical Research, 10, 157-162.

[15] Apex2 (2006) Version 2 User Manual, M86-E01078, Bruker Analytical X-Ray Systems Madison, WI.

[16] Siemens, S.S. (1995) Siemens Analytical X-Ray Instruments Inc. Madison, MI.

[17] Sheldrick, G. (2007) SADABS, Bruker AXS, Inc. Madison, WI.

[18] Sheldrick, G. (2008) A Short History of SHELX. Acta Crystallographica A, 64, 112-122. https://doi.org/10.1107/S0108767307043930

[19] Sheldrick, G. (2015) Crystal Structure Refinement with SHELXL. Acta Crystallographica C, 71, 3-8. https://doi.org/10.1107/S2053229614024218

[20] Spek, A. (2003) Single-Crystal Structure Validation with the Program PLATON. Journal of Applied Crystallography, 36, 7-13. https://doi.org/10.1107/S0021889802022112

[21] Macrae, C.F., Bruno, I.J., Chisholm, J.A., Edgington, P.R., McCabe, P. and Pidcock, E. (2008) Mercury CSD 2.0-New Features for the Visualization and Investigation of Crystal Structures. Journal of Applied Crystallography, 41, 466-470. https://doi.org/10.1107/S0021889807067908

[22] Spackman, M.A. and Jayatilaka, D. (2009) Hirshfeld Surface Analysis. CrystEngComm, 11, 19-32. https://doi.org/10.1039/B818330A

[23] Wolff, S., Grimwood, D., McKinnon, J., Turner, M., Jayatilaka, D. and Spackman, M. (2012) Crystal Explorer. The University of Western Australia, Crawley.

[24] Groom, C.R., Bruno, I.J., Lightfoot, M.P. and Ward, S.C. (2016) The Cambridge Structural Database. Acta Crystallographica B, 72, 171-179. https://doi.org/10.1107/S2052520616003954

[25] Shet Prakash, M., Suchetan, P.A., Mahadevan, K.M., Vaidya, V.P., Velumurgan, D. and Palakshamurthy, B.S. (2013) Ethyl 5-Bromo-naphtho-[2,1-b]furan-2-carboxylate. Acta Crystallographica E, 69, o198. https://doi.org/10.1107/S160053681205204X

[26] Shruthi, E., Kumar, S.M., Kusuma, K., Manjunath, H.R., Vaidya, V.P., Sridhar, M.A. and Lokanath N.K. (2012) Synthesis and Structural Studies of Ethylnaphtho[2,1-b]furan-2-carboxylate. X-Ray Structure Analysis Online, 28, 23-24. https://doi.org/10.2116/xraystruct.28.23

[27] Arici, C., Kirilmis, C., Koca, M. and Heinemann, F.W. (2006) (3-Methyl-3-phenylcyclo-butyl)(naphtho[2,1-b]furan-2-yl)methanone. Acta Crystallographica E, 62, o2783. https://doi.org/10.1107/S1600536806021398

[28] Fun, H.-K., Loh, W.-S., Malladi, S., Ganesh, B.M. and Isloor, A.M. (2011) $\mathrm{N}^{\prime}$-[(E)-(3-Phenyl-1H-pyrazol-4-yl)methyl-idene]naphtho-

[2,1-b]furan-2-carbohydrazide monohydrate. Acta Crystallographica E, 67, o3471. https://doi.org/10.1107/S1600536811050239

[29] Shet Prakash, M., Suchetan, P.A., Palakshamurthy, B.S., Mahadevan, K.M. and Vaidya V.P. (2011) N-(Phenyl-sulfon-yl)naphtha-[2,1-b]furan-1-carboxamide. Acta Crystallographica E, 67, o3491. https://doi.org/10.1107/S1600536811050495 